\title{
Hospitalização por bronquiolite aguda como fator de risco para sibilância recorrente
}

\author{
Hospitalization for bronchiolitis: \\ a risk factor for recurrent wheezing
}

Elaine P. Albernaz 1

Ana Maria B. Menezes 2

Juraci A. César 3

Cesar G. Victora 4

Fernando C. Barros 4

\footnotetext{
1 Departamento MaternoInfantil, Faculdade de Medicina, Universidade Federal de Pelotas. Av. Duque de Caxias 250 3 o andar, Pelotas, $R S$ 96030-002, Brasil. zanrebla@ufpel.tche.br 2 Departamento de Clínica Médica, Faculdade de Medicina, Universidade Federal de Pelotas. Av. Duque de Caxias 250 3 o andar, Pelotas, $R S$ 96030-002, Brasil. 3 Departamento MaternoInfantil, Faculdade de Medicina, Universidade do Rio Grande. Rua Eng. Alfredo Huck 475, Rio Grande, $R S$ 96201-460, Brasil. 4 Departamento de Medicina Social, Faculdade de Medicina, Universidade Federal de Pelotas. Av. Duque de Caxias 250, 3 o andar, Pelotas, RS 96030-002, Brasil.
}

\begin{abstract}
This longitudinal study evaluated the role of hospitalization for acute bronchiolitis as a risk factor for recurrent wheezing. Participants were children from a 1993 cohort in a southern Brazilian city. Hierarchical multivariate analysis showed that previous hospitalization for bronchiolitis was the most important risk factor for recurrent wheezing, with an odds ratio of 4.9. This strong association is consistent with a casual relationship hypothesis.

Key words Hospitalization; Bronchiolitis; Child; Child Health

Resumo Foi realizado um estudo longitudinal para avaliar o papel da hospitalização por bronquiolite aguda como fator de risco para sibilância recorrente. Os participantes foram crianças de uma cidade no sul do Brasil, pertencentes à coorte de 1993. A análise multivariada hierarquizada mostrou que a hospitalização prévia por bronquiolite foi o fator de risco mais importante para sibilância recorrente, com uma razão de produtos cruzados de 4,9. Esta forte associação é consistente com a hipótese de relação causal.

Palavras-chave Hospitalização; Bronquiolite; Criança; Saúde Infantil
\end{abstract}




\section{Introdução}

A bronquiolite aguda é uma das causas mais comuns de infecção nos primeiros anos de vida, atingindo cerca de $15 \%$ das crianças até dois anos de idade, sendo responsável pela hospitalização de cerca de dois em cada 100 lactentes (Sung et al., 1992).

Vários estudos sugerem que crianças hospitalizadas por bronquiolite têm risco aumentado de apresentar seqüela pulmonar (Kattan et al., 1977; Sims et al., 1981; McConnochie \& Roghmann, 1985; Milner \& Murray, 1989), caracterizada principalmente por tosse e sibilância recorrente (McConnochie \& Roghmann, 1984; Welliver et al., 1986a; Murray et al., 1992; Panitch et al., 1993; Kuikka et al., 1994; Sigurs et al., 1995). Permanece controverso se a infecção causaria dano ao pulmão em crescimento ou se haveria alterações prévias da via aérea, tornando algumas crianças mais suscetíveis a desenvolverem a infecção (Martinez et al., 1988; Everard \& Milner, 1992; Young et al., 1995).

A sibilância recorrente pode acarretar maior número de visitas a serviços de pronto-atendimento e, até mesmo, reinternações, com todas as repercussões físicas e emocionais que poderão afetar a qualidade de vida das crianças.

Embora a história familiar de asma brônquica ou atopia apresente associação com o desenvolvimento de asma brônquica (Behrman et al., 1996), esta não parece estar associada com o desenvolvimento de seqüela pulmonar pós-bronquiolite aguda; tal fato foi demonstrado em alguns trabalhos, como o de Sigurs et al. (1995), que realizaram estudo prospectivo com crianças hospitalizadas por bronquiolite aguda e evidenciaram um risco oito vezes maior de elas desenvolverem sibilância recorrente, quando comparadas a controles com a mesma história familiar para asma. Da mesma forma, Murray et al. (1992), em estudo prospectivo, compararam crianças com hospitalização prévia por bronquiolite no primeiro ano de vida a um grupo-controle e não encontraram diferença estatisticamente significativa entre os dois grupos em relação à história familiar de asma ou atopia para o desfecho sibilância pós-bronquiolite.

Alguns estudos realizados com o objetivo de avaliar a associação entre hospitalização por bronquiolite e sibilância recorrente sofreram limitações, como, por exemplo, inadequado controle para fatores de confusão e número considerável de perdas. O presente estudo pretende contribuir para essa avaliação, mediante a análise da ocorrência de sibilância recorrente em crianças com hospitalização prévia por bronquiolite comparadas a um grupo-controle de crianças pertencentes à mesma coorte que não foram hospitalizadas por este motivo.

\section{Metodologia}

Este é um estudo longitudinal aninhado à coorte de 1993, da qual fizeram parte todas as crianças nascidas nesse ano, na cidade de Pelotas. Esta coorte foi constituída por quatro subestudos, cada qual com metodologia e logística específicas, a saber: perinatal, acompanhamentos (um, três, seis e doze meses), morbidade e mortalidade (Victora et al., 1996).

No estudo perinatal eram feitas visitas diárias aos cinco hospitais da cidade, identificando-se todos os nascimentos ocorridos. As mães eram entrevistadas através de questionário padronizado, visando à obtenção de informações a respeito de condições sócio-econômicas e ambientais, história reprodutiva materna, dados demográficos, além de assistência pré e perinatal. Era efetuada uma avaliação antropométrica do recém-nascido e calculada a idade gestacional por intermédio do método de Dubowitz (Dubowitz et al., 1970).

O estudo de acompanhamento teve como objetivo avaliar a evolução das crianças com um, três, seis e 12 meses de idade. Foram realizadas visitas domiciliares, ocasião em que as mães eram entrevistadas e as crianças, pesadas e medidas. Os acompanhamentos de um e três meses foram executados em amostra de $10 \%$ das crianças da coorte; contudo, nos dois últimos acompanhamentos (seis e 12 meses) foram visitadas $20 \%$ das crianças e aquelas que nasceram com baixo peso.

O estudo de morbidade investigou o total das admissões hospitalares das crianças nascidas em Pelotas, em 1993. A equipe visitava diariamente todos os hospitais da cidade. As mães eram entrevistadas, o prontuário revisado e, quando necessário, era realizada entrevista com o médico. Considerou-se, como critério de hospitalização, a permanência da criança em ambiente hospitalar por período superior a 24 horas. A causa da internação era determinada por dois árbitros independentes, com base nas informações obtidas. Em caso de discordância, um terceiro árbitro emitia o seu parecer. Quando este concordava com um dos árbitros, o diagnóstico ficava estabelecido; persistindo a discordância, havia uma reunião entre os três, que debatiam até chegarem ao diagnóstico. Os diagnósticos foram codificados conforme a 9a Classificação Internacional de Doenças (OMS, 1980). 
No atual estudo, tentou-se localizar, em 1996, todas as crianças que haviam sido hospitalizadas por bronquiolite no período pós-neonatal (113) e um grupo de crianças-controle (226). Foram excluídas crianças com malformações congênitas e fibrose cística. As crianças do grupo controle foram selecionadas do estudo de acompanhamento mediante sorteio. Aplicou-se um questionário com perguntas acerca da saúde infantil, acrescido de questões referentes ao histórico de doença pulmonar da criança e avaliação do aparelho respiratório, com base no Children's Questionnaire ATSDLD-78-C (Ferris, 1978).

\section{Critério diagnóstico}

O diagnóstico de bronquiolite foi baseado em achados clínicos, incluindo os seguintes: sibilância expiratória de início agudo, ausência de história prévia, sinais de doença respiratória viral - tais como: coriza, tosse ou febre - acompanhados de dificuldade respiratória (Mcconnochie \& Roghmann, 1984, 1985, 1986; Morris et al., 1990; Mulholland et al., 1990; Skoner et al.,1990; Murray et al., 1992; Sung et al., 1992; Sigurs et al., 1995). Sibilância recorrente foi definida como duas ou mais crises de chiado no peito que causassem falta de ar, cansaço ou dificuldade para respirar.

\section{Amostragem}

O tamanho da amostra obtida - 105 expostos e 210 não-expostos à hospitalização por bronquiolite - mostrou-se suficiente para detectar um risco relativo de 2 , com nível de significância de $5 \%$ e com poder de $95 \%$.

\section{$\underline{\text { Análise }}$}

A análise inicial foi feita de modo a buscar-se associações entre os fatores de risco e a presença de sibilância recorrente através do cálculo da razão de incidências cumulativas e de seu intervalo de confiança de 95\%. Esta análise bivariada foi efetuada somente no grupo de 210 crianças que não haviam sido hospitalizadas. O objetivo foi identificar os fatores que se mostraram associados ao desfecho sibilância recorrente (com p valor $\leq 0,20$ ) e que seriam levados para a análise multivariada. Excluíramse os 105 casos com hospitalização prévia por bronquiolite aguda, pois isso acarretaria viés de seleção, isto é, haveria desvio nos resultados obtidos, pois sua inclusão no estudo estava vinculada à exposição. Os fatores que seriam identificados como de risco para sibilância recor- rente seriam, muito provavelmente, aqueles determinantes da hospitalização por bronquiolite aguda.

Procedeu-se à análise multivariada para as 210 crianças não-expostas e, após, para as 315 crianças, incluindo-se, no último nível do modelo, a variável hospitalização por bronquiolite. A seleção de fatores na regressão logística foi feita de acordo com modelo teórico que hierarquiza as inter-relações entre os diversos grupos de fatores (Victora et al., 1994, 1997; Fuchs et al., 1996) (Figura 1). De acordo com este modelo, fatores nos níveis superiores da hierarquia influenciam o desfecho através de efeito independente e/ou efeito intermediado por fatores nos níveis inferiores. Isto se traduz, na prática de análise, pela avaliação do efeito dos fatores de interesse ajustados apenas para os fatores de confusão pertencentes a nível hierárquico igual ou superior ao seu.

Assim, os fatores sócio-econômicos que pertencem ao primeiro nível - juntamente com as variáveis demográficas -, entraram no primeiro passo da análise multivariada. O segundo nível compreendeu as características maternas e fatores ambientais. O terceiro nível foi composto pelos fatores nutricionais, história familiar de atopia e asma brônquica. No quarto nível, como fator determinante proximal, foi acrescida hospitalização por bronquiolite.

Foram considerados possíveis fatores de confusão aquelas variáveis que mostraram estar associadas com a exposição, com o desfe-

Figura 1

Modelo de análise.

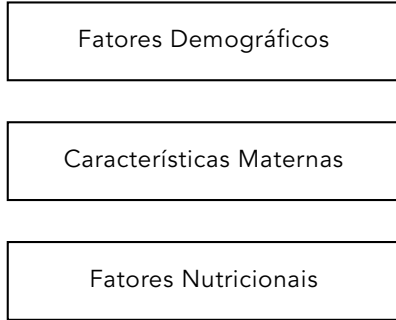

Fatores Ambientais

História Familiar
Hospitalização por Bronquiolite

Sibilância Recorrente 
cho, sem serem elo na cadeia causal que vinculava a exposição com o desfecho, com $\mathrm{p} \leq 0,20 \mathrm{e}$ diferença entre a odds bruta e a ajustada $\geq 10 \%$.

\section{Resultados}

De um total de 339 crianças selecionadas (226 pertencentes ao grupo de não-expostos e 113 do grupo de expostos), foram visitadas 315 , sendo que 105 haviam sido hospitalizadas previamente por bronquiolite e 210 pertenciam ao grupo controle. As perdas do estudo totalizaram 7\%: 0,9\% devido a óbitos (uma criança-índice e duas controle), 1,8\% por endereço não localizado e $4,4 \%$ por mudança de cidade.

A faixa etária das crianças no momento da hospitalização por bronquiolite ficou assim distribuída: entre 28 e 89 dias, 39\%; entre 90 e 179 dias, $48 \%$; e entre 180 e 364 dias, 13\%. Ao serem revisitadas, em 1996, a média de idade das 315 crianças era de 33 meses. A idade no momento da hospitalização não se mostrou associada ao desfecho sibilância recorrente. Entre as crianças sem história prévia de hospitalização por bronquiolite, 23,3\% apresentaram sibilância recorrente, ao passo que, para aquelas que haviam sido hospitalizadas, o índice foi de $61,9 \%$.

O número de dados ignorados (missing) foi pequeno, mostrando-se inferior a $5 \%$ nas variáveis em que estes ocorreram, e foram recodificados como a moda. Em decorrência do grande número de fatores avaliados, somente aqueles que mostraram estar associados com o desfecho, com $\mathrm{p}$ valor $\leq 0,20$, foram apresentados nas tabelas.

A Tabela 1 mostra a distribuição das crianças não hospitalizadas por bronquiolite, com e sem sibilância recorrente, de acordo com as características demográficas, sócio-econômicas e reprodutivas. Observa-se que não houve associação do desfecho com a variável sexo. O risco para sibilância recorrente mostrou-se menor nas crianças de cor branca, ao serem comparadas às pretas e mulatas. Em relação à renda familiar, o risco foi duas vezes maior no grupo de renda entre 1,1 e 3 salários-mínimos; semelhante ao ocorrido na avaliação quanto à escolaridade materna, sendo o grupo de maior risco aquele cujas mães tinham menor escolaridade. A variável classe social não foi incluída na análise, pois algumas categorias não tinham nenhuma criança como representante. Entre as variáveis reprodutivas, apenas paridade mostrou associação ao desfecho estatisticamente significativa, com relação diretamente proporcional ao risco.
A distribuição das variáveis ambientais conforme a análise bivariada encontra-se na Tabela 2. Houve aumento de $90 \%$ no risco para sibilância entre as crianças cujas casas não tinham água encanada em seu interior. Quanto aos fatores relacionados à aglomeração, observou-se que o risco de sibilância recorrente foi 2,5 vezes maior quando três ou mais pessoas dormiam no mesmo quarto que a criança, semelhante ao encontrado quando outra criança com menos de cinco anos de idade morava na casa. O risco de apresentar o desfecho duplicou quando o número de moradores era igual ou superior a cinco. Em relação à exposição ao fumo passivo, esta foi avaliada de várias formas (presença de qualquer fumante em casa, mãe fumante, número total de cigarros consumidos no interior da casa e número total de cigarros consumidos pela mãe, dentro de casa); no entanto, somente fumo materno (atual ou após o nascimento da criança) mostrou associação estatisticamente significativa com o desfecho, aumentando o risco em $74 \%$.

A avaliação de história familiar de atopia e de asma brônquica entre os parentes de primeiro grau (pais e irmãos) evidenciou que apenas uma história familiar de asma brônquica apresentou associação, embora bastante fraca, mas suficiente para ser incluída na análise multivariada conforme o nível de significância. As variáveis escolaridade materna e número de pessoas que dormem no quarto da criança apresentaram tendência linear.

Outros fatores que foram estimados - mas não contemplados nas tabelas por não terem associações com o desfecho cujo nível de significância fosse $\leq 0,20$ - foram: idade materna, ganho de peso materno durante a gestação, idade gestacional, peso de nascimento, aleitamento materno, estado nutricional atual da criança, tipo de construção, de piso e de aquecimento da casa e freqüência à creche.

A análise multivariada (Tabela 3) incluiu as variáveis associadas com o desfecho, com $\mathrm{p}$ valor de até 0.20 , conforme a análise bivariada. Inicialmente ajustou-se a variável "cor da criança” para "renda familiar" e "escolaridade materna”, observando-se que a associação com o desfecho mostrou-se no limiar da significância estatística. A "renda familiar", ao ser ajustada para "cor" e "escolaridade materna" (presumindo-se que haja relação entre variáveis do mesmo nível), apresentou redução nos valores da razão de produtos cruzados (odds ratio) ajustados em relação aos brutos, demonstrando que parte de seu poder explicativo era devido à "escolaridade materna”. O mesmo ajuste fez com que a "escolaridade materna" fosse excluída do 
Ocorrência de sibilância recorrente entre as crianças sem hospitalização prévia por bronquiolite, conforme as características demográficas, sócio-econômicas e reprodutivas. Pelotas, Rio Grande do Sul (1997).

\begin{tabular}{|c|c|c|c|c|c|c|}
\hline \multirow[t]{2}{*}{ Variável } & \multicolumn{2}{|c|}{ Crianças sibilantes } & \multicolumn{2}{|c|}{ Crianças não-sibilantes } & \multirow[t]{2}{*}{$\operatorname{RR}(I C 95 \%)^{\star}$} & \multirow[t]{2}{*}{$p$ valor } \\
\hline & $n=49$ & $\%$ & $n=161$ & $\%$ & & \\
\hline Sexo & & & & & & 0,93 \\
\hline Masculino & 24 & 49,0 & 80 & 49,7 & 1,00 & \\
\hline Feminino & 25 & 51,0 & 81 & 50,3 & $1,02(0,63-1,67)$ & \\
\hline Cor & & & & & & 0,01 \\
\hline Branca & 34 & 69,4 & 137 & 85,1 & 1,00 & \\
\hline Preta/mulata & 15 & 30,6 & 24 & 14,9 & $1,93(1,18-3,18)$ & \\
\hline Renda familiar & & & & & & 0,03 \\
\hline$>3 \mathrm{sm}^{\star \star}$ & 19 & 38,8 & 97 & 60,2 & 1,00 & \\
\hline $1,1-3 \mathrm{sm}$ & 25 & 51,0 & 51 & 31,7 & $2,01(1,19-3,38)$ & \\
\hline$\leq 1 \mathrm{sm}$ & 5 & 10,2 & 13 & 8,1 & $1,70(0,72-3,97)$ & \\
\hline Escolaridade materna & & & & & & 0,09 \\
\hline$\geq 9$ anos & 7 & 14,3 & 43 & 26,7 & 1,00 & \\
\hline $5-8$ anos & 26 & 53,1 & 85 & 52,8 & $1,67(0,78-3,60)$ & \\
\hline$\leq 4$ anos & 16 & 32,7 & 33 & 20,5 & $2,33(1,05-5,17)$ & \\
\hline Paridade & & & & & & 0,01 \\
\hline 1 & 10 & 20,4 & 58 & 36,0 & 1,00 & \\
\hline 2 & 10 & 20,4 & 49 & 30,4 & $1,15(0,52-2,58)$ & \\
\hline 3 & 17 & 34,7 & 29 & 18,0 & $2,51(1,27-4,99)$ & \\
\hline$\geq 4$ & 12 & 24,5 & 25 & 15,5 & $2,21(1,05-4,61)$ & \\
\hline
\end{tabular}

* $\mathrm{RR}(\mathrm{IC} 95 \%)$ = risco relativo e intervalo de confiança de $95 \%$.

** $\mathrm{sm}=$ salário mínimo.

modelo ( $\mathrm{p}$ valor $=0,44)$. Quanto à paridade, ao ser ajustada para as variáveis do primeiro nível e para as demais do mesmo nível, perdeu a significância estatística de sua associação com sibilância recorrente.

Das variáveis referentes à aglomeração, observou-se que a presença de outra criança na residência, com idade inferior a cinco anos, manteve-se associada com o desfecho sibilância recorrente, mesmo após o ajuste para as demais variáveis (do primeiro e segundo nível). Entretanto, o ajuste acarretou diminuição significativa da medida de risco quando comparada com o valor bruto. As variáveis "número total de moradores" e "número de pessoas que dormem no quarto da criança" não se mantiveram associadas com sibilância recorrente.

"Presença de água encanada dentro de casa" e "história familiar de asma brônquica" perderam a significância estatística de sua associação com o desfecho, com p valor superior a 0,20. "Exposição ao fumo materno" foi mantida no modelo, com p valor de 0,11 .
A Tabela 4 mostra o resultado da análise multivariada realizada com todas as 315 crianças. A análise incluiu todas as variáveis apresentadas na Tabela 3, acrescentando-se, no último nível, a variável "hospitalização por bronquiolite aguda” ao modelo. Controlando para: cor, renda familiar, presença de outra criança com idade inferior a cinco anos morando na casa e exposição a fumo materno, observou-se que o risco de apresentar sibilância recorrente foi cinco vezes maior nas crianças que haviam sido hospitalizadas por bronquiolite aguda. A medida bruta e a ajustada são semelhantes, mostrando não só a magnitude como a não-interferência significativa de outros fatores de risco na associação.

Em razão da alta prevalência da variável dependente (23\% nos não-expostos), visando-se maior rigor metodológico e sabendo-se que a razão de prevalência (RP) é sempre mais próxima da unidade (efeito nulo) do que a razão de produtos cruzados (RPC), realizou-se a conversão da RPC em RP (Osborn \& Cattaruzza, 1994). 
Ocorrência de sibilância recorrente entre as crianças sem hospitalização prévia por bronquiolite, conforme as características ambientais e história familiar de asma brônquica. Pelotas, Rio Grande do Sul (1997).

\begin{tabular}{|c|c|c|c|c|c|c|}
\hline \multirow[t]{2}{*}{ Variável } & \multicolumn{2}{|c|}{ Crianças sibilantes } & \multicolumn{2}{|c|}{ Crianças não-sibilantes } & \multirow[t]{2}{*}{ RR (IC 95\%)* } & \multirow[t]{2}{*}{$\mathrm{p}$ valor } \\
\hline & $n=49$ & $\%$ & $n=161$ & $\%$ & & \\
\hline $\begin{array}{l}\text { Água encanada } \\
\text { dentro de casa }\end{array}$ & & & & & & 0,03 \\
\hline Sim & 38 & 77,6 & 144 & 89,4 & 1,00 & \\
\hline Não & 11 & 22,4 & 17 & 10,6 & $1,88(1,10-3,23)$ & \\
\hline $\begin{array}{l}\text { Número de pessoas que } \\
\text { dormem com a criança }\end{array}$ & & & & & & 0,006 \\
\hline$\leq 1$ & 8 & 16,3 & 47 & 29,2 & 1,00 & \\
\hline 2 & 17 & 34,7 & 73 & 45,3 & $1,30(0,60-2,81)$ & \\
\hline$\geq 3$ & 24 & 49,0 & 41 & 25,5 & $2,54(1,24-5,19)$ & \\
\hline $\begin{array}{l}\text { Presença de outra criança } \\
<\text { de } 5 \text { anos }\end{array}$ & & & & & & 0,001 \\
\hline Não & 24 & 49,0 & 124 & 77,0 & 1,00 & \\
\hline $\operatorname{Sim}$ & 25 & 51,0 & 37 & 23,0 & $2,49(1,55-4,00)$ & \\
\hline Total de moradores & & & & & & 0,005 \\
\hline $2-4$ & 19 & 38,8 & 99 & 61,5 & 1,00 & \\
\hline$\geq 5$ & 30 & 61,2 & 62 & 38,5 & $2,03(1,22-3,36)$ & \\
\hline Fumo materno & & & & & & 0,03 \\
\hline Não & 22 & 44,9 & 101 & 62,7 & 1,00 & \\
\hline Sim & 27 & 55,1 & 60 & 37,3 & $1,74(1,06-2,84)$ & \\
\hline $\begin{array}{l}\text { História familiar } \\
\text { de asma brônquica }\end{array}$ & & & & & & 0,18 \\
\hline Não & 23 & 46,9 & 93 & 57,8 & 1,00 & \\
\hline Sim & 26 & 53,1 & 68 & 42,2 & $1,40(0,85-2,28)$ & \\
\hline
\end{tabular}

Com isto, ocorreu redução da RPC de 4,94 para uma RP de 2,59. Uma vez que não houve confundimento da associação de interesse pelos fatores estudados (a variação foi inferior a $10 \%$ ), calculou-se também a RP bruta, a qual foi 2,65 (intervalo de confiança 1,99-3,54).

\section{Discussão}

O principal objetivo deste estudo foi avaliar a presença ou não de seqüela pulmonar após hospitalização por bronquiolite aguda, controlando possíveis fatores de confusão. A alta prevalência de sibilância recorrente $(61,9 \%)$ em crianças com hospitalização prévia por bronquiolite - em relação às que não foram hospitalizadas $(23,3 \%)$ - ressalta a importância do estudo e está de acordo com dados de literatura.

Um aspecto importante desta discussão diz respeito à definição dos critérios diagnósticos utilizados tanto para bronquiolite aguda como para seqüela pós-bronquiolite. A maioria dos estudos aponta critérios clínicos para o diagnóstico destas duas entidades. "Primeiro episódio de chiado em crianças menores de dois anos, precedido por sinais de doença respiratória viral como coriza, tosse ou febre, mais a presença de dificuldade respiratória" (McConnochie \& Roghman, 1985:626), preenchem os critérios clínicos para estabelecer o diagnóstico de bronquiolite. Com base nestes dados clínicos é que o diagnóstico de bronquiolite aguda deste estudo foi estabelecido. Outro aspecto a ressaltar é o fato de que dois árbitros independentes participaram deste processo, o que conferiu ao trabalho maior rigor. Além disso, esta etapa da pesquisa aconteceu durante o estudo de morbidade realizado no primeiro ano de vida das crianças da coorte e, portanto, não poderia ter causado qualquer viés no atual estudo. 
Quanto à seqüela pós-bronquiolite, os principais sintomas descritos na literatura são de hiper-reatividade brônquica, traduzida por sibilância recorrente e outros sintomas respiratórios, tais como tosse. Apesar de testes mais sensíveis para medir hiper-reatividade, não foi possível executá-los no presente estudo, em virtude de questões logísticas e de ordem financeira. Sendo assim, a presença de duas ou mais crises de chiado no peito, com falta de ar, cansaço ou dificuldade para respirar, foi o critério clínico definido para avaliar hiper-reatividade brônquica. Para tanto, foram utilizadas perguntas do Children's Questionnaire ATS$D L D-78-C$, como já haviam feito McConnochie \& Roghmann (1984) e Young et al. (1995).

O pequeno número de perdas do estudo é outro aspecto que merece ser salientado, pois foi inferior ao de outros estudos de acompanhamento (Kattan et al., 1977; McConnochie \& Roghmann, 1985; Murray et al., 1992).

A forte associação entre hospitalização por bronquiolite no período pós-neonatal e sibilância recorrente demonstrada neste estudo é consistente com a hipótese de relação causal. Vários outros fatores de risco tiveram testada sua relação com o desenvolvimento de sibilância recorrente, mas a hospitalização prévia por bronquiolite manteve-se como o fator de risco mais importante. Além disso, ao realizar-se a análise multivariada, testando-se outras hipóteses alternativas e plausíveis, estas não afetaram de forma significativa tal relação.

É interessante observar que, de todas as variáveis relacionadas ao fumo passivo, somente fumo materno mostrou associação com sibilância recorrente, embora estatisticamente não-significativa, após ser submetida a análise multivariada. Murray et al. (1992) destacaram o fumo materno como fator de risco para sibilância pós-bronquiolite. Welliver et al. (1986b) encontraram associação significativa entre sibilância recorrente e exposição ao fumo passivo, não especificamente o materno, ainda que outros autores não tenham evidenciado tal relação (Welliver et al., 1986a; Sigurs et al., 1995).

Embora a literatura mostre que meninos sibilam mais do que as meninas (Pullan \& Hey, 1982; Welliver et al., 1986a), tal associação não foi aqui demonstrada. Panitch et al. (1993) apontaram história familiar de asma e de atopia como fatores de risco para sibilância recorrente pós-bronquiolite. Entretanto, neste estudo, predisposição hereditária para atopia ou asma brônquica não se mostrou como explicação provável para o desfecho, pois tanto os casos quanto os controles apresentaram fatores hereditários similares, e este achado é seme-
Tabela 3

Análise multivariada para sibilância recorrente entre as crianças sem hospitalização prévia por bronquiolite, conforme modelo hierárquico. Pelotas, Rio Grande do Sul (1997).

\begin{tabular}{|c|c|c|c|}
\hline Variável & $\mathrm{ORb}^{*}(\mathrm{IC} 95 \%)$ & ORa** (IC 95\%) & $p$ valor \\
\hline Corr*** & & & 0,06 \\
\hline Branca & 1,00 & 1,00 & \\
\hline Preta/mulata & $2,52(1,12-5,66)$ & $2,13(0,98-4,63)$ & \\
\hline Renda familiar ${ }^{\star \star \star}$ & & & 0,16 \\
\hline$>3 \mathrm{sm}^{\star \star \star \star}$ & 1,00 & 1,00 & \\
\hline $1,1-3 \mathrm{sm}$ & $2,50(1,19-5,26)$ & $2,01(0,97-4,17)$ & \\
\hline$\leq 1 \mathrm{sm}$ & $1,96(0,54-6,90)$ & $1,20(0,34-4,21)$ & \\
\hline $\begin{array}{l}\text { Presença de outra } \\
\text { criança }<5 \text { anos } \\
\star \star \star \star \star\end{array}$ & & & 0,04 \\
\hline Não & 1,00 & 1,00 & \\
\hline Sim & $3,49(1,70-7,21)$ & $2,44(1,06-5,59)$ & \\
\hline Fumo materno $o^{\star \star \star \star \star}$ & & & 0,11 \\
\hline Não & 1,00 & 1,00 & \\
\hline Sim & $2,07(1,03-4,15)$ & $1,80(0,88-3,69)$ & \\
\hline
\end{tabular}

* odds ratio bruta; ** odds ratio ajustada; *** Modelo 1: cor, renda familiar e escolaridade materna; ${ }^{\star \star \star \star} \mathrm{sm}=$ salário mínimo; ${ }^{\star \star \star \star \star}$ Modelo 2: cor, renda familiar, paridade, presença de água dentro da casa, número de pessoas que dormem com a criança, presença de outra criança menor de cinco anos de idade, total de moradores e fumo materno.

Tabela 4

Análise multivariada para sibilância recorrente, conforme modelo hierárquico, para a amostra de 315 crianças. Pelotas, Rio Grande do Sul (1997).

\begin{tabular}{lccc}
\hline Variável & ORb (IC 95\%) & ORa (IC 95\%) & p valor \\
\hline $\begin{array}{l}\text { Hospitalização } \\
\text { por bronquiolite* } \\
\text { Não }\end{array}$ & & & $<0,001$ \\
Sim & 1,00 & 1,00 & \\
& $5,34(3,12-9,17)$ & $4,94(2,94-8,30)$ &
\end{tabular}

* Ajustado para: cor, renda familiar, presença de outra criança menor de cinco anos e fumo materno.

lhante ao de outros estudos (Sims et al., 1978, 1981; Murray et al., 1992; Sigurs et al., 1995).

Fatores relacionados à aglomeração - tais como "número de pessoas no quarto da criança", "presença de outra criança menor de cinco anos na residência" e "tamanho da família" têm sido citados como de risco para aumentar a exposição a vírus (Pullan \& Hey, 1982). Estes fatores têm sido mais apontados como de risco para a hospitalização por bronquiolite, mas pouco avaliados para sibilância recorrente. 
Martinez et al. (1988, 1995, 1996) sugerem, em vários estudos, que existiriam alterações iniciais da via aérea, tornando algumas crianças predispostas a apresentarem sibilância em associação com infecções respiratórias virais, além de postular que, na maioria dos casos, essa seria situação transitória. Entretanto, estudos como os de Kattan et al. (1977) e Sims (1978) reportaram reatividade brônquica em indivíduos avaliados dez e oito anos, respectivamente, após o episódio agudo de bronquiolite.

\section{Referências}

BEHRMAN, R. E.; KLIEGMAN, R. M.; ARVIN, A. M. \& NELSON, W. E., 1996. Textbook of Pediatrics. 15th Ed. Philadelphia: W. B. Saunders Company.

DUBOWITZ, L. M. S.; DUBOWITZ, V. \& GOLDBERG, C., 1970. Clinical assessment of gestational age in the newborn infant. Journal of Pediatrics, 77:1-10.

EVERARD, M. L. \& MILNER, A. D., 1992. The respiratory syncytial virus and its role in acute bronchiolitis. European Journal of Pediatrics, 151:638-651.

FERRIS, B. G., 1978. Epidemiology Standardization Project. American Review of Respiratory Disease, 118:1-120.

FUCHS, S. C.; VICTORA, C. G. \& FACHEL, J., 1996. Modelo hierarquizado: Uma proposta de modelagem aplicada à investigação de fatores de risco para diarréia grave. Revista de Saúde Pública, 30: 168-178.

KATTAN, M.; KEENS, T. G.; LAPIERRE, J. G.; LEVISON, H.; BRYAN, C. \& REILLY, B. J., 1977. Pulmonary function abnormalities in symptom-free children after bronchiolitis. Pediatrics, 59:683-688.

KUIKKA, L.; REIJONEN, T.; REMES, K. \& KORPPI, M. 1994. Bronchial asthma after early childhood wheezing: A follow-up until 4.5-6 years of age. Acta Paediatrica, 83:744-748.

MARTINEZ, F. D.; WAYNE, J. M.; WRIGHT, A. L.; HOLBERG, C. J.; TAUSSIG, L. M. \& THE GROUP HEALTH MEDICAL ASSOCIATED PERSONNEL, 1988. Diminished lung function as a predisposing factor for wheezing respiratory illness in infants. New England Journal of Medicine, 319:1112-1117.

MARTINEZ, F. D.; WRIGHT, A. L.; TAUSSIG, L. M.; HOLBERG, C. J.; HALONEN, M.; MORGAN, W. J. \& THE GROUP HEALTH MEDICAL ASSOCIATED PERSONNEL, 1995. Asthma and wheezing in the first six years of life. New England Journal of Medicine, 332:133-138.
Concluindo, a hospitalização por bronquiolite no período pós-neonatal parece ser importante fator de risco para o desenvolvimento de sibilância recorrente. Um aspecto interessante a ser investigado é se a infecção causa anormalidades na função pulmonar ou se a infecção, no primeiro ano de vida, identifica os indivíduos que têm pequenas vias aéreas e, por conseguinte, são congenitamente predispostos à obstrução.

MARTINEZ, F. D.; WRIGHT, A. L.; TAUSSIG, L. M.; HOLBERG, C. J.; HALONEN, M.; MORGAN, W. J. \& THE GROUP HEALTH MEDICAL ASSOCIATED PERSONNEL, 1996. Bronchiolitis and asthma in infancy and early chilhood. Thorax, 51 (Sup. 2): 60-64.

McCONNOCHIE, M. K., 1983. Bronchiolitis. What's in the name? American Journal of Diseases in Childhood, 137:11-13.

McCONNOCHIE, M. K. \& ROGHMANN, K. J., 1984. Bronchiolitis as a possible cause of wheezing in childhood: New evidence. Pediatrics, 74:1-10.

McCONNOCHIE, M. K. \& ROGHMANN, K. J., 1985. Predicting clinically significant lower respiratory tract illness in childhood following mild bronchiolitis. American Journal of Diseases in Childhood, 139:625-631.

McCONNOCHIE, M. K. \& ROGHMANN, K. J., 1986. Parental smoking, presence of older sibilings, and family history of asthma increase risk of bronchiolitis. American Journal of Diseases in Childhood, 140:806-812.

MILNER, A. D. \& MURRAY, M., 1989. Acute bronchiolitis in infancy: Treatment and prognosis. Tho$\operatorname{rax}, 44: 1-5$.

MORRIS, K.; MORGANLANDER, M.; COULEHAN, J. L.; GAHAGEN, S. \& ARENA, V. C., 1990. Woodburning stoves and lower respiratory tract infection in American indian children. American Journal of Diseases in Childhood, 144:105-108.

MULHOLLAND, E. K.; OLINSKY, A. \& SHANN, F. A., 1990. Clinical findings and severity of acute bronchiolitis. Lancet, 335:1259-1261.

MURRAY, M.; WEBB, M. S. C.; O'CALLAGHAN, C.; SWARBRICK, A. S. \& MILNER, A. D., 1992. Respiratory status and allergy after bronchiolitis. Archives of Disease in Childhood, 67:482-487. 
OMS (Organização Mundial de Saúde), 1980. Classificação Internacional de Doenças. Revisão 1975. São Paulo: Centro da Organização Mundial de Saúde para Classificação de Doenças em Português.

OSBORN, J. \& CATTARUZZA, M. S., 1994. Odds ratio and relative risk for cross-sectional data. International Journal of Epidemiology, 24:464-465.

PANITCH, H. B.; CALLAHAN, C. W. \& SCHIDLOW, D. V., 1993. Bronchiloitis. Clinics in Chest Medicine, 14:715-731.

PULLAN, C. R. \& HEY, E. N., 1982. Wheezing, asthma, and pulmonary dysfunction 10 years after infection with respiratory syncytial virus in infancy. $B M J, 284: 1665-1669$.

SIGURS, N.; BJARNASON, R.; SIGURBERGSSON, F.; KJELLMAN, B. \& BJÖRKSTÉN, B., 1995. Asthma and immunoglobulin $\mathrm{E}$ antibodies after respiratory syncytial virus bronchiolitis: A prospective cohort study with matched controls. Pediatrics, 95:500-505.

SIMS, D. G.; DOWNHAM, M. A. P. S.; GARDNER, P. S.; WEBB, J. K. G. \& WEIGHTMAN, D., 1978. Study of 8-year-old children with a history of respiratory syncytial virus bronchiolitis in infancy. BMJ, 1:1114.

SIMS, D. G.; GARDNER, P. S.; WEIGHTMAN, D.; TURNER, M. W. \& SOOTHILL, J. F., 1981. Atopy does not predispose to RSV bronchiolitis or postbronchiolitic wheezing. BMJ, 282:2086-2088.

SKONER, D. P.; FIREMAN, P.; CALIGUIRI, L. \& DAVIS, H., 1990. Plasma elevations of histamine and a prostaglandin metabolite in acute bronchiolitis. American Review of Respiratory Disease, 142:359364.
SUNG, R. Y. T.; CHAN, R. C. K.; TAM, J. S.; CHENG, A. F. B. \& MURRAY, H. G. S., 1992. Epidemiology and aetiology of acute bronchiolitis in Hong Kong infants. Epidemiology and Infection, 108:147-154.

VICTORA, C. G.; BARROS, F. C.; HALPERN, R.; MENEZES, A. M. B.; HORTA, B. L.; TOMASI, E.; WEIDERPASS, E.; CESAR, J. A.; OLINTO, M. T.; GUIMARÃES, P. R. V.; GARCIA, M. M. \& VAUGHAN, J. P., 1996. Estudo longitudinal da população materno-infantil de Pelotas, localidade da região sul do Brasil, 1993: Aspectos metodológicos e resultados preliminares. Revista de Saúde Pública, 30:34-35.

VICTORA, C. G.; FUCHS, S. C.; FLORES, J. A. C.; FONSECA, W. \& KIRKWOOD, B., 1994. Risk factors for pneumonia among children in a Brazilian metropolitan area. Pediatrics, 93:977-985.

VICTORA, C. G.; HUTTLY, S. R.; FUCHS, S. C. \& OLINTO, M. T. A., 1997. The role of conceptual frameworks in epidemiological analysis: A hierarchical approach. International Journal of Epidemiology, 26:224-227.

WELLIVER, R. C.; SUN, M.; RINALDO, D. \& OGRA, P. L., 1986a. Predictive value of respiratory syncytial virus-specific IgE responses for recurrent wheezing following bronchiolitis. Journal of Pediatrics, 109:776-780.

WELLIVER, R. C.; WONG, D. T.; SUN, M. \& McCARTHY, N., 1986b. Parainfluenza virus bronchiolitis. American Journal of Diseases in Childhood, 140: 34-40.

YOUNG, S.; O'KEEFFE, P. T.; ARNOTT, J. \& LANDAU, L. I., 1995. Lung function, airway responsiveness, and respiratory symptoms before and after bronchiolitis. Archives of Disease in Childhood, 72:1624 . 